\title{
Clinical, Radiological and Histological Features of Calcifying Epithelial Odontogenic Tumor: Case Report
}

\author{
Maria Cristina Zindel DEBONI ${ }^{1}$ \\ Maria da Graça NACLÉRIO-HOMEM ${ }^{1}$ \\ Décio Santos PINTO JUNIOR ${ }^{2}$ \\ Andréia Aparecida TRAINA ${ }^{1}$ \\ Marcelo Gusmão Paraíso CAVALCANTI ${ }^{3}$ \\ ${ }^{1}$ Department of Oral and Maxillofacial Surgery; ${ }^{2}$ Department of Pathology; ${ }^{3}$ Department of Radiology, \\ Faculty of Dentistry, University of São Paulo, São Paulo, SP, Brazil
}

\begin{abstract}
The calcifying epithelial odontogenic tumor (CEOT) is a rare benign odontogenic neoplasm that accounts for approximately $1 \%$ of all odontogenic tumors. Its origin is controversial as well as its true malignant potential. A case of an advanced CEOT associated with an impacted right second molar in the mandible of a young black female patient is presented. Computed tomography imaging, radiographic and pathological findings, surgical patterns, gross anatomy of the lesion and the performed treatment are discussed.
\end{abstract}

Key Words: calcifying epithelial odontogenic tumor, computed tomography, mandible.

\section{INTRODUCTION}

Nearly 200 cases of calcifying epithelial odontogenic tumor (CEOT) have been reported in the literature (1) since Pindborg described it as a separate pathologic entity in 1955 (2). It has been identified under different denominations, such as ameloblastoma of unusual type with calcification, calcifying ameloblastoma, malignant odontoma and cystic complex odontoma, and has also been considered as a variant of simple ameloblastoma (2). The eponym Pindborg Tumor was first introduced to the literature in 1967 to describe this interesting and unique odontogenic tumor $(3,4)$.

The CEOT is a benign odontogenic tumor of epithelial origin that accounts for approximately $1 \%$ of all odontogenic tumors and characteristically contains calcifying masses or homogeneous acellular material within the tumor epithelium and stroma $(3,5,6)$. The origin of this neoplasm is controversial, though it is generally accepted to be derived from the oral epithelium, reduced enamel epithelium, stratum intermedium or dental lamina remnants. The differential diagnosis for CEOT should include adenomatoid odontogenic tumor, calcifying odontogenic cyst, ameloblastic fibroodontoma and odontoma $(1,2)$.

This paper describes the case of an advanced CEOT with unusual features associated with an impacted right second molar in the mandible of a young black female patient. The correlations between clinical, radiological and histological patterns are discussed and a brief review of literature is presented.

\section{CASE REPORT}

A 16-year-old black female presented at the Oral Surgery Department of the Faculty of Dentistry of the University of São Paulo (FOU-SP, Brazil) with a chief complaint of pain and swelling involving the inferior right facial region. She referred to four months of pain and gradual swelling associated with fever. A great

Correspondence: Profa. Dra. Maria Cristina Zindel Deboni, Departamento de Cirurgia, Traumatologia e Prótese Buco-Maxilo-Facial, Faculdade de Odontologia de São Paulo, Universidade de São Paulo, Av. Prof. Lineu Prestes 2227, Cidade Universitária, 05508-900 São Paulo, SP, Brasil. Tel/Fax: +55-11-3091-7832. E-mail: mczdebon@usp.br 
discomfort had been felt in the affected region even before the swelling was noted. Her medical history revealed convulsive episodes during childhood that had been treated by phenobarbital (Gardenal; Avantis Pharma, São Paulo, SP, Brazil; 50 mg/day).

Upon extraoral examination, a 5-cm facial asymmetry was noted with a smooth, hard and fixed swelling the at right anterior mandible. Intraoral examination revealed buccal and lingual cortical expansion at the canine, premolar and molar mandibular regions with dislocation and mobility of the mandibular first molar and absence of the second and the third molars of the same side. Oral mucosa was intact but slightly erythematous.

A panoramic radiograph revealed a large, well demarcated lytic lesion involving the right body of mandible, extending anteriorly to the right first premolar, with a very thin cortex and resorption of first molar roots. The second molar was dislocated to the inferior border of the mandible while the third molar was displaced posteriorly (Fig. 1). Computed tomography (CT) imaging showed a well-circumscribed isodense mass with anteroposterior and lateromedial expansion of the cortices containing irregular stellate opacities with bone erosion (Figs. 2 and 3). Contrast enhancement attenuation was observed involving the posterior portion of the lesion. Lingual cortex fenestration, multilocular spaces, vascularity and radiopaque masses were also observed in the CT images (Fig. 2).

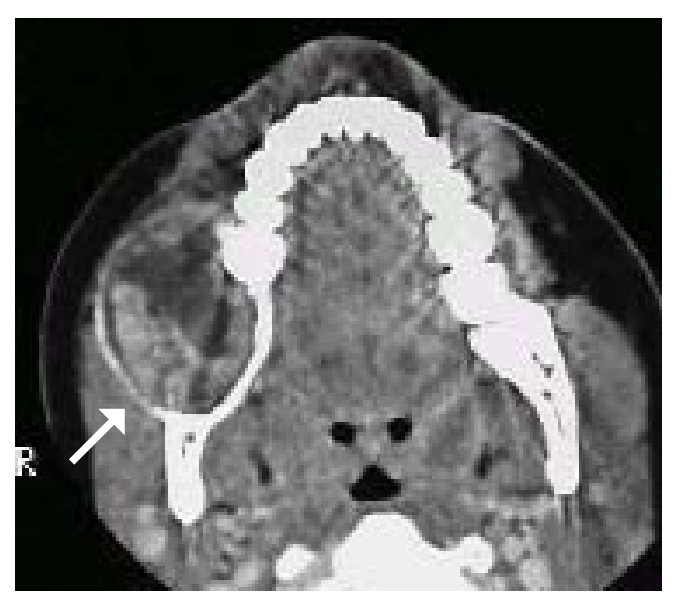

Figure 2. Axial computed tomography image at soft tissue level demonstrating the anteroposterior extension of the tumor and showing the vascularity at the posterior portion of the lesion (arrow).
After the incisional biopsy, the microscopic examination revealed an epithelial neoplasm composed of sheets and nests of polyhedral epithelial cells with an abundant eosinophilic, granular cytoplasm. Cellular outlines were distinct and intercellular bridges were noted. Considerable nuclear polymorphism was a frequent finding. Extracellular amyloid-like substance and calcified concentric deposits (the so-called Liesegang rings) were also identified (Figs. 4 and 5).

The treatment of choice was right mandible segmental resection with titanium plate reconstruction. The gross examination of the surgical resection revealed a cystic cavity filled with blood, focal areas of yellowish vegetations and extra-osseous tumoral mass, surrounded by a myxomatous capsule. During specimen bisection, calcified particles were frequently observed producing a crunching sound while cutting (Fig. 6).

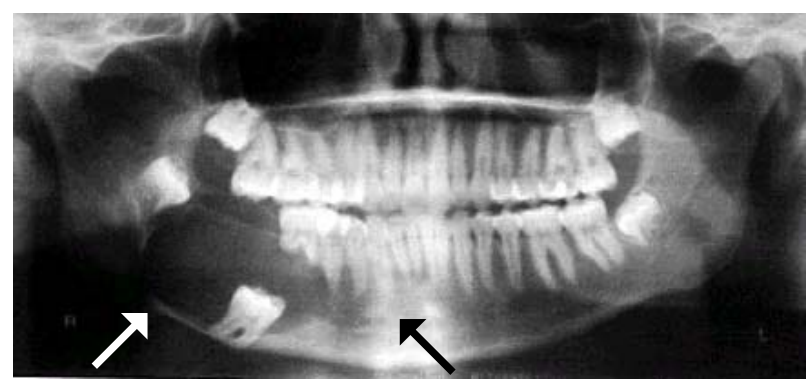

Figure 1. Panoramic radiograph showing a large and welldemarcated lytic lesion involving the right body of mandible, extending from the second molar to the first premolar (arrows).

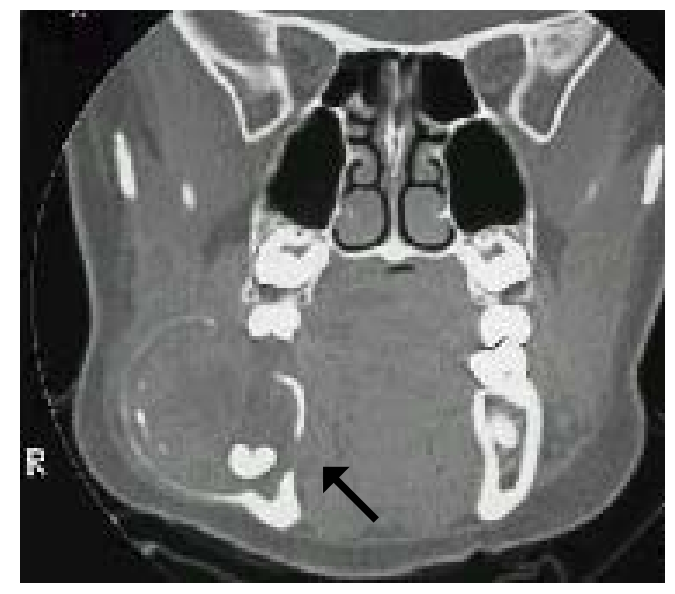

Figure 3. Coronal computed tomography image at bone level showing the relationship between the impacted tooth and the lesion. Lateromedial expansion and lingual bone erosion can also be observed (arrow). 


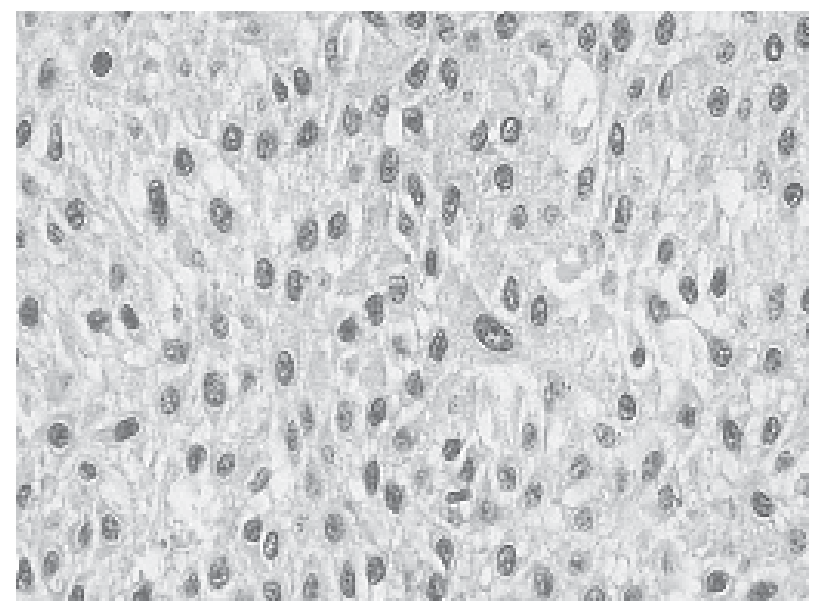

Figure 4. Microscopic view of the epithelial neoplasm composed of sheets and nests of polyhedral epithelial cells with an abundant eosinophilic and granular cytoplasm (Hematoxylin and eosin staining; original magnification $400 \mathrm{X}$ ).

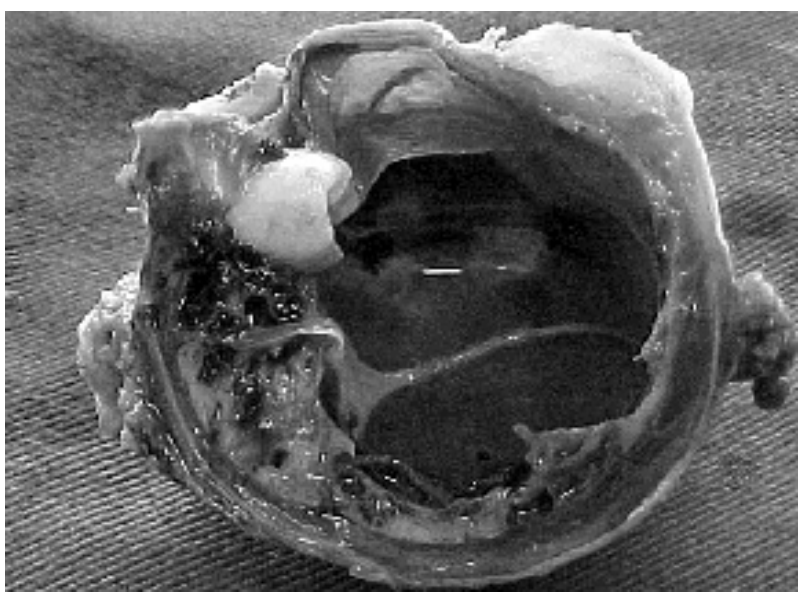

Figure 6. Macroscopic view of the surgical resection depicting the second molar involved by the tumor with some bleeding areas, a great cortical expansion and the bone cavity with septae.

\section{DISCUSSION}

The literature reports that this intraosseous tumor usually manifests as a painless swelling that causes slow bone expansion (2-4,7). However, the case described presented as a painful swelling perhaps due to its great extension, associated infection and compression of the inferior alveolar nerve. It has been shown that in 67 cases of CEOT only 13\% of the patients complained of pain or discomfort (3). When located in the maxilla, patients may sometimes complain of nasal

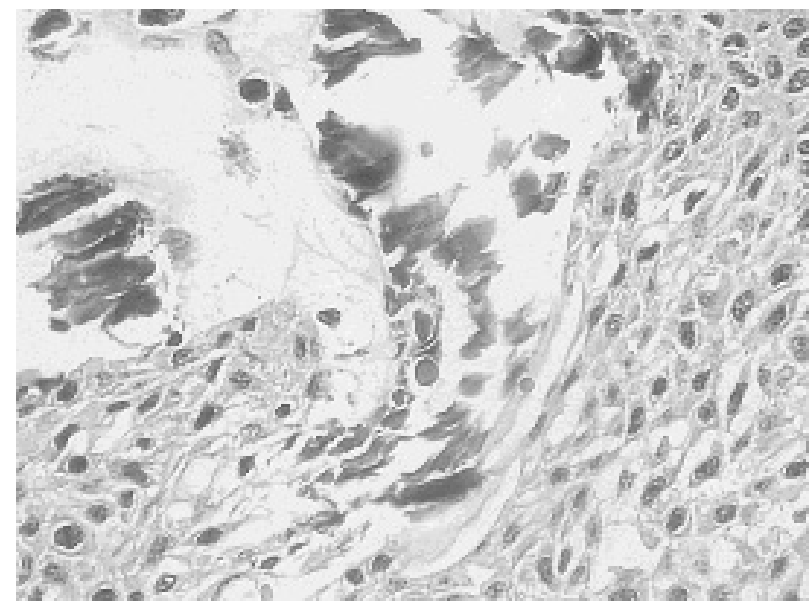

Figure 5. Microscopic view of nuclear pleomorphism and extracellular amyloid-like substance and calcified concentric deposits - Liesegang rings (Hematoxylin and eosin staining; original magnification 400X).

stuffiness, epistaxis and headache $(2,7)$.

There is a wide variation in clinical, radiological and histological aspects. Most investigators agree that the central type is usually located in the premolar and molar regions, with a mandibular to maxillary ratio of 2:1 or $3: 1(1,3,4)$. Most CEOT cases, nearly $52 \%$, are associated with impacted or unerupted teeth or odontomas $(1-3,6)$. The prevalence in the molar region is 3 times greater than that of the premolar area (1) and only some cases have been found around first and second molars (3). This article describes an unusual lesion involving the second molar of a black female patient at the second decade of life. However, the age range of patients with CEOT varies between 8 and 92 years (mean age of 36.9 years) at the time of diagnosis. Kaplan et al. (3) showed a female predilection of 1.5:1 in 67 cases, with peak age in the fourth and fifth decades, and lesion occurrence in different groups with a slight predilection for Caucasian individuals (1).

The lesion usually consists of a radiolucent area, which may be well or poorly defined, uni or multilocular, containing radiopaque masses of varying size and opacity $(2,4,5,7)$. In several cases, especially in tumors of relatively short duration, the calcification is very small and may be undetectable on radiographs. When an unerupted tooth is associated with the tumor, the radiopacities tend to be located close to tooth crown (2).

In the case hereby reported, the CT images revealed important characteristics that were not detected 
by panoramic radiography, such as detection of multilocular spaces and lingual cortex fenestration and calcifications (Figs. 2 and 3). The visualization of the internal structure of the lesion and the involvement of neighboring structures were considered very helpful for clinical diagnosis and treatment planning.

Although root resorption is an uncommon finding, it was observed in the present case. Kaplan et al. (3) reported root resorption in $4 \%$ of 67 cases and emphasized that this feature may aid in the differential diagnosis between CEOT and solid ameloblastoma. CEOT is a benign tumor whose biological behavior was once believed to be similar to that of ameloblastoma. It is generally described as a slow growing mass, occasionally associated with a long history of evolution $(2,7)$. However, in most cases, there is actually little information on tumor duration and therefore the true growth rate of the tumor is uncertain (3). The evaluation of this case can be considered relatively short with rapid growth of tumor mass. This fact, together with cortical rupture and its vascularity, could suggest a more aggressive nature of this particular tumor. Moreover, this case had some features that could suggest malignancy like those reported in previous papers that addressed cases of lesions diagnosed as CEOT $(7,8)$.

The treatment for CEOT has ranged from simple enucleation or curettage to radical and extensive resection such as hemimandibulectomy or hemimaxillectomy $(1,2)$. The choice should be individualized for each lesion because the radiological and histological features may differ from one lesion to another. Since the case reported was of great extension and rapid evolution, the treatment was right mandible segmental resection and titanium plate reconstruction. It could be possible to correlate some characteristics of the gross examination of the surgical resection, like cystic cavity filled with blood, calcified particles, lingual cortex fenestration, multilocular spaces and vascularity, to those found in CT images (Fig. 2, 3, and 6).

The prognosis of the CEOT is good with infrequent recurrence. Malignant behavior is extremely rare. Although it has not been established in the literature, five years should be the absolute minimum follow-up necessary to assess the healing for this type of odontogenic tumor (2).

Further case reports might correlate similar data to the above-mentioned aspects, which could produce a fairly detailed description of the epidemiologic profile of this unique odontogenic tumor. Overall, a range of clinical, imaging and histopathological findings should be used to help the diagnosis of CEOT, to evaluate its extension in different sites and to show the correlation of the lesion components in the different exams.

\section{RESUMO}

O tumor odontogênico epitelial calcificante (TOEC) é uma neoplasia odontogênica rara de natureza benigna, representando aproximadamente $1 \%$ de todos os tumores odontogênicos. Sua origem é controversa bem como seu potencial de transformação maligna. Esse artigo relata um caso avançado de TOEC associado a um segundo molar direito incluso na mandíbula deuma paciente negra jovem. As imagens de tomografia computadorizada, achados radiográficos e patológicos, padrões cirúrgicos, aspectos anatômicos lesão e o tratamento realizado são discutidos.

\section{ACKNOWLEDGEMENTS}

This study was supported by a grant-in-aid from CNPq to Dr. Marcelo Cavalcanti (Process N. 309331/2003-0).

\section{REFERENCES}

1. Bouckaert MMR, Raubenheimer EJ, Jacobs FJ. Calcifying epithelial odontogenic tumor with intracranial extension: report of a case and review of the literature. Oral Surg Oral Med Oral Pathol Oral Radiol Endod 2000;90:656-662.

2. Philipsen HP, Reichart PA. Calcifying epithelial odontogenic tumour: biological profile based on 181 cases from the literature. Oral Oncology 2000;36:17-26.

3. Kaplan I, Buchner A, Calderon S, Kaffe I. Radiological and clinical features of calcifying epithelial odontogenic tumour. Dentomaxillofac Radiol 2001;30:22-28.

4. Houston GD, Fowler CB. Extraosseous calcifying epithelial odontogenic tumor: report of two cases and review of the literature. Oral Surg Oral Med Oral Pathol Oral Radiol Endod 1997;83:577-583.

5. Cross JJL, Pilkington RJJ, Antoun NM, Adlam DM. Value of computed tomography and magnetic resonance imaging in the treatment of a calcifying epithelial odontogenic (Pindborg) tumour. Br J Oral Maxillofac Surg 2000;38:154157.

6. Negri P, Riccioni S, Lomurno G. Raro tumore odontogeno epiteliale calcificante o tumore di Pindborg. Minerva Stomatol 1999;48:353-357.

7. Cheng YSL, Wright JM, Walstad WR, Finn MD. Calcifying epithelial odontogenic tumor showing microscopic features of potential malignant behavior. Oral Surg Oral Med Oral Pathol Oral Radiol Endod 2002;93:287-295.

8. Veness MJ, Morgan G, Collins AP, Walker DM. Calcifying epithelial odontogenic (Pindborg) tumor with malignant transformation and metastatic spread. Head Neck 2001;23:692-696.

Accepted October 13, 2005 